\title{
Early results after mitral valvuloplasty for pure mitral regurgitation
}

\author{
A. Gallino, R. Jenni, R. Hurni, H. O. Hirzel, H. P. Krayenbühl, L. Egloff, M. Rothlin, \\ M. SCHÖNBECK AND M. TURINA \\ Departments of Medicine and Heart Surgery, University Hospital Zürich, Switzerland
}

KEY WORDS: Mitral regurgitation, mitral valve reconstruction, mitral valve replacement.

In this study we present the results of 105 consecutive patients with pure mitral regurgitation who underwent surgical treatment. In all patients mitral regurgitation was associated with mitral valve prolapse: 54 patients underwent mitral valvuloplasty and 51 patients mitral valve replacement.

Clinical assessment and echocardiography were used as follow-up criteria at one year after surgery. After mitral valvuloplasty, $N Y H A$ decreased from $2.7 \pm 0.8$ to $1.1 \pm 0.7(\mathrm{P}<0.01)$ and workload capacity increased from $65 \pm 28 \%$ to $96 \pm 25 \%(\mathrm{P}<0.001)$; left endsystolic atrial dimension and enddiastolic dimension decreased from $6 \cdot 2 \pm 0.8$ to $4 \cdot 8 \pm 1 \cdot 2 \mathrm{~cm}(\mathrm{P}<0.001)$ and from $7 \cdot 2 \pm 1 \cdot 3$ to $5.9 \pm 0 \cdot 8 \mathrm{~cm}(\mathrm{P}<0.01)$; ventricular contraction fraction did not change significantly.

After mitral valve replacement, clinical and echocardiographic improvement was significant but less remarkable than after valvuloplasty; ventricular contraction fraction fell from $39 \pm 7 \%$ to $29 \pm 8 \%$ in contrast to patients undergoing mitral valvuloplasty in whom no significant change occurred.

Complications were rare in both groups though only a minority of patients undergoing mitral valvuloplasty received anticoagulants. We conclude that mitral valvuloplasty in patients with pure mitral regurgitation associated with mitral valve prolapse gives excellent results, particularly regarding left ventricular function when compared with the patients after mitral valve replacement.

\section{Introduction}

At our institution, mitral valvuloplasty (MV) was introduced by Åke Senning in the early nineteen sixties; the procedure was then almost abandoned during the nineteen seventies favouring mitral valve replacement (MVR). Since the convincing results of Carpentier et al. ${ }^{[1.2]}$ were published $\mathrm{MV}$ regained a valid place in treatment of our patients with pure mitral regurgitation.

Mitral valvuloplasty in patients with mitral regurgitation associated with mitral valve prolapse (MVP) offers an alternative to mitral valve replacement and may avoid the potential complications of a prosthetic valve ${ }^{[1-3]}$. We present here the results of a study of 54 consecutive patients with pure mitral regurgitation associated with mitral prolapse undergoing MV with insertion of a Carpentier ring. All patients were followed for one year and the result of

Submitted for publication on 14 October 1986 and in revised form 9 February 1987

Address for correspondence Augusto Gallino, Department of Medicine, University Hospital, CH-8091 Zürich, Switzerland. operation was assessed by clinical examination and non-invasive evaluation. Particular attention was paid to echocardiography which has been recently demonstrated to be a valid means for the evaluation of the postoperative result in these patients ${ }^{[4-6]}$.

The results after $M V$ were then compared with those of a comparable group of 51 patients, who underwent mitral valve replacement (MVR) because of pure MR also associated with mitral prolapse (MP) performed by the same surgical team during the same time period.

\section{Patients and methods}

A total of 105 consecutive patients with pure MR associated with MVP underwent heart surgery between January 1983 and January 1986. A total of 54 patients underwent $\mathrm{MV}$ whereas 51 patients underwent MVR. Both procedures were performed by the same heart surgeons (M.T. and L.E.). The patients were not randomly allocated to MV or to MVR; but the operative procedure was decided on by the heart surgeon for each particular patient. 
Table 1 Preoperative clinical, haemodynamic and surgical data

\begin{tabular}{|c|c|c|c|c|c|c|c|c|c|}
\hline & $N$ & Age & $\begin{array}{l}\text { MR } \\
(\%)\end{array}$ & $\begin{array}{c}\text { LA or PCW } \\
\text { (v-wave) } \\
\text { (mmHg) }\end{array}$ & $\begin{array}{l}\text { LVEDP } \\
(\mathrm{mmHg})\end{array}$ & $\begin{array}{l}\mathrm{EF} \\
(\%)\end{array}$ & $\frac{\mathrm{CO}}{\left(1 \mathrm{~min}^{-1} \mathrm{~m}^{-2}\right)}$ & $\begin{array}{l}\text { CPB } \\
\text { time } \\
(\min )\end{array}$ & $\begin{array}{c}\text { AC } \\
\text { time } \\
\text { (min) }\end{array}$ \\
\hline $\begin{array}{l}\text { MV } \\
\text { MVR }\end{array}$ & $\begin{array}{l}54 \\
51\end{array}$ & $\begin{array}{l}54 \pm 11 \\
58 \pm 10\end{array}$ & $\begin{array}{l}57 \pm 14 \\
60 \pm 11\end{array}$ & $\begin{array}{l}35 \pm 15 \\
30 \pm 17\end{array}$ & $\begin{array}{l}12 \pm 6 \\
15 \pm 8\end{array}$ & $\begin{array}{l}56 \pm 8 \\
51 \pm 9\end{array}$ & $\begin{array}{l}2.4 \pm 0.6 \\
2 \cdot 1 \pm 0.7\end{array}$ & $\begin{array}{l}92 \pm 28 \\
82 \pm 24\end{array}$ & $\begin{array}{l}36 \pm 10 \\
32 \pm 13\end{array}$ \\
\hline
\end{tabular}

$M V=$ mitral valvuloplasty, $M V R=$ mitral valve replacement, $M R=$ mitral regurgitation, $L A=$ left atrial pressure, $\mathrm{PCW}=$ pulmonary capillary wedge pressure, $\mathrm{LVEDP}=$ left ventricular enddiastolic pressure, $\mathrm{EF}=$ ejection fraction, $\mathrm{CO}=\mathrm{cardiac}$ output, $\mathrm{CPB}=$ cardiopulmonary bypass, $\mathrm{AC}=$ aortic clamp

Table 2 Preoperative and postoperative follow-up obtained by clinical assessment and echocardiography

\begin{tabular}{|c|c|c|c|c|c|c|c|}
\hline & NYHA & CTR & WC $(\%)$ & $\operatorname{LAD}(\mathrm{cm})$ & $\operatorname{EDD}(\mathrm{cm})$ & $\operatorname{vef}(\%)$ & af \\
\hline \multicolumn{8}{|l|}{$M V(N=54)$} \\
\hline Preoperative & $2 \cdot 7 \pm 0 \cdot 8$ & $0.56 \pm 0.07$ & $65 \pm 28$ & $6.2 \pm 0.8$ & $7 \cdot 2 \pm 1 \cdot 3$ & $37 \pm 5$ & 21 \\
\hline Postoperatuve & $1 \cdot 1 \pm 0.7^{*}$ & $0.46 \pm 0.08$ & $96 \pm 25^{*}$ & $4 \cdot 8 \pm 1 \cdot 2^{*}$ & $5 \cdot 9 \pm 0.8^{*}$ & $35 \pm 6$ & 15 \\
\hline \multicolumn{8}{|l|}{$M V R(N=51)$} \\
\hline Preoperative & $2 \cdot 6 \pm 0.7$ & $0.57 \pm 0.05$ & $57 \pm 18$ & $5 \cdot 8 \pm 1 \cdot 1$ & $7 \cdot 3 \pm 0.9$ & $39 \pm 7$ & 16 \\
\hline Postoperative & $1.4 \pm 0.6^{*}$ & $0.50 \pm 0.06^{*}$ & $89 \pm 14^{* *}$ & $4.9 \pm 1 \cdot 2^{* * *}$ & $5.9 \pm 0.9^{* *}$ & $29 \pm 8^{* *}$ & 12 \\
\hline
\end{tabular}

$C T R=$ cardiothoracic ratio, $W C=$ work capacity in $\%$ of expected, $L A D=$ left atrial dimension, EDD $=$ left ventricular enddiastolic dimension, $\mathrm{vcf}=$ ventricular contraction fraction, af $=$ atrial fibrillation

${ }^{*} P<001, * * P<0.05$ when compared to the preoperative values postoperative follow-up time was $11 \pm 2 \mathrm{mths}$ and $9 \pm 1.6 \mathrm{mths}$ for MV and MVR, respectively.

Patients with other concomitant valvular disease or coronary artery disease as well as patients with valve calcification were excluded from the study.

MV with insertion of a Carpentier ring was performed using previously described technique including leaflet resection, chordal shortening and/ or fenestration ${ }^{[1,2]}$. MVR was performed by the same surgical team using a mechanical prosthesis in 29 patients and a biological prosthesis in 22 patients. All patients had preoperative cardiac catheterization; preoperative clinical, haemodynamic and surgical data of the patients with MV as well of the control group with MVR are given in Table 1.

Preoperative assessment as well as follow-up at 12 months after operation included clinical evaluation using NYHA criteria, chest X-ray (measurement of cardiotheracic ratio), ECG and ECG-stress test for determining the work capacity (WC) and echocardiography. M-mode echocardiography (Organon Technika $224 \mathrm{Mfo}$ ) and cross-sectional echocardiography (Diasonics CV $3400 \mathrm{R}$ ) with a standard transducer $(2.25 \mathrm{MHz})$ were performed for every patient by the same investigator (R.J.). Left endsystolic atrial dimension (LAD), left ventricular enddiastolic (EDD) and endsystolic (ESD) dimensions as well as ventricular contraction fraction (VCF) were measured for every patient.

In patients with MV, acetylsalisylic acid (ASA), $\left(1200 \mathrm{mg} \mathrm{day}^{-1}\right)$ was given only in the presence of atrial fibrillation. Patients with mechanical MVR received oral anticoagulants postoperatively whereas patients with biological MVR received anticoagulants only in the presence of atrial fibrillation.

The paired $t$-test was used for comparing the results before and after operation; $t$-test was used for comparing the results between patients with MV and MVR.

\section{Results}

CLINICAL FINDINGS (TABLE 2)

After MV there was a remarkable clinical improvement: Clinical symptoms (NYHA), workload 
capacity (WC) and cardiothoracic ratio (CTR) improved from $2.7 \pm 0.8,65 \pm 28 \%$ and $0.56 \pm 0.07$ to $1.1 \pm 0.7(P<0.01), 96 \pm 25 \%(P<0.001)$ and $0.46 \pm 0.08(P<0.01)$, respectively.

After MVR there was also a significant improvement in these clinical parameters but, with the exception of NYHA, the improvement was less pronounced than after MV $(P<0.05)$.

The incidence of atrial fibrillation in patients after MV was $10 / 35(28 \%)$ and similar to that in patients after MVR 7/29 (23\%).

\section{ECHOCARDIOGRAPHIC FINDINGS (TABLE 2,}

FIGS I AND 2)

After MV there was also a major improvement of left atrial dimension (LAD) and enddiastolic dimension (EDD) than after MVR: LAD and EDD fell from $6 \cdot 2 \pm 0.8$ and $7 \cdot 2 \pm 1 \cdot 3$ to $4.8 \pm 1.2$ $(P<0.01)$ and $5.9 \pm 0.8 \quad(P<0.01)$ respectively. Ventricular contraction fraction (VCF) did not change significantly after $\mathrm{MV}$; whereas there was a significant fall in VCF from $39 \pm 7 \%$ to $29 \pm 8 \%$ $(P<0.05)$ after MVR.

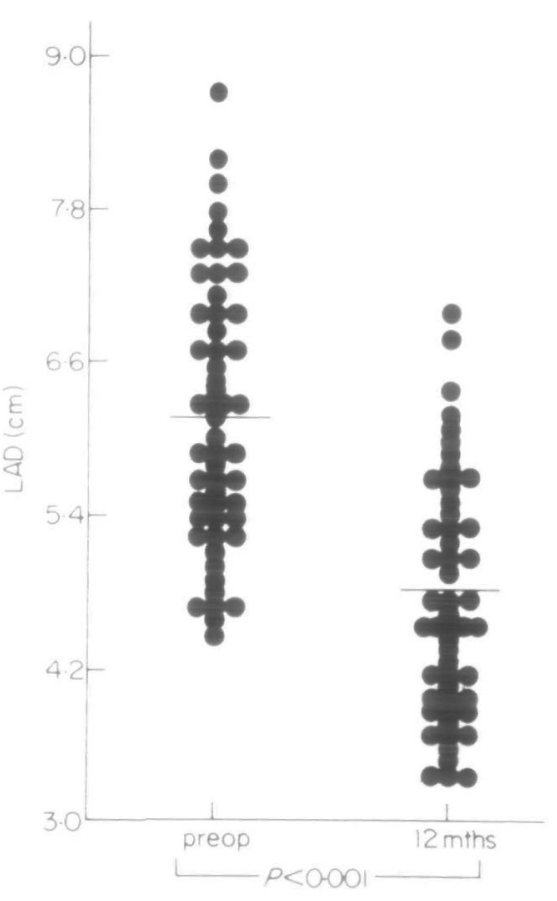

Figure I Left atrial dimension (LAD) before and 12 months after mitral valvuloplasty (MV).

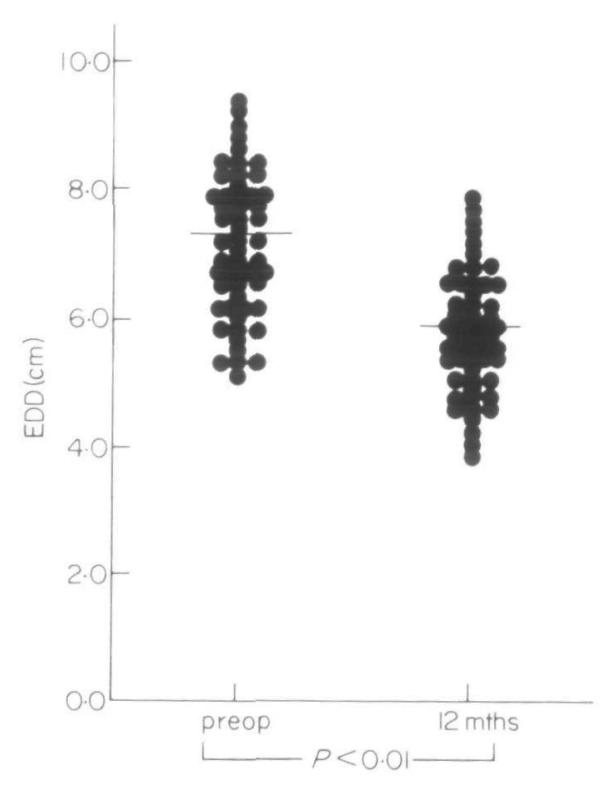

Figure 2 Left ventricular enddiastolic dimension (EDD) before and 12 months after mitral valvuloplasty (MV).

\section{Complications}

After MV, one death occurred 4 days after operation in a 72 year old patient because of sudden death in asystole: there were no other deaths after MV during the duration of the study. Reoperation was necessary 4 days after MV because of postoperative severe subaortic stenosis documented by echocardiography, angiography and pressure measurements in one patient without any evidence of this lesion preoperatively. Transitory ischaemic attacks (TIA) occurred in four patients reporting transitory visual disturbance (two patients were on anticoagulation); in 1 patient with postoperative atrial fibrillation complete stroke with aphasia and right hemiparesis occurred under anticoagulation.

In patients with MVR there was also one sudden death in a 61 year old patient 12 months after operation: there were 5 patients with TIA and one patient with a complete stroke.

In one patient, endocarditis occurred 6 months after MVR (bioprosthesis) and was successfully treated by medical therapy; no patient developed endocarditis after MV.

\section{Discussion}

Our results show that MV represents a valid and safe procedure for the treatment of patients with 
pure MV associated with MVP giving excellent early results which are comparable and even better than those after MVR particularly regarding left ventricular function ${ }^{[7-9]}$. Complications and particularly thromboembolic events after MV were rare as well as in the control group with MVR though only a minority of patients undergoing MV received anticoagulants. The fact that patients were not randomized to MV or MVR may limit the value of our results. However, there was no significant difference in preoperative clinical and haemodynamic findings between the two groups of patients and in both groups MR was always associated with MVP giving consistency to our results. The incidence of postoperative atrial fibrillation was also similar in both groups of patients.

After MVR ventricular contraction fraction (VCF) decreased significantly whereas in patients undergoing MV no deterioration of VCF occurred. In contrast to MVR, MV allows the preservation of the continuity between the mitral annulus and left ventricular wall through the chordae tendinae and papillary muscles which seem to play an important role in left ventricular function ${ }^{[10]}$ and may explain the better outcome in our patients after MV.

Severe subaortic stenosis requiring reoperation developed in one patient 4 days after MV. This uncommon complication has been reported previously ${ }^{[1,12]}$. In our patient haemodynamic evaluation before and after the myectomy procedure proved the beneficial effect of reoperation.

Through the number of patients and particularly the follow-up time are not sufficient to allow a definite statement, $M V$ seems to represent a valid operative approach for patients with pure MR associated with MVP with even better early results than in patients undergoing MVR. Whether patients with pure MR not associated with MVP may also benefit from $M V$ remain questionable; this will need to be verified by further studies.

\section{References}

[1] Carpentier A, Deloche A, Dauptain J et al. A new reconstructive operation for correction of mitral and tricuspid insufficiency. J Thorac Cardiovasc Surg 1971; 61: 1.

[2] Carpentier A, Chauvaud S, Fabiani JN et al. Reconstructive surgery of mitral valve incompetence. J Thorac Cardiovasc Surg 1980; 79: 388.

[3] Schmidli J, Rothlin ME, Turina $M$ et al. Langzeitresultate nach Mitralklappenoperation wegen Mitralinsuffizienz 1972-1982. Schweiz Med Wschr 1985; 115: 430.

[4] Kronzon I, Mercurio P, Winer HW el al. Echocardiographic evaluation of Carpentier mitral valvuloplasty. Am Heart J 1983; 106: 362.

[5] Danilowicz D, Kronzon I, Doyle EF et al. Echocardiographic patterns after mitral anuloplasty. Cardiology 1980; 65: 129.

[6] Hurni R, Hirzel HO, Jenni R et al. Pure mitral valve insufficiency: Early and late postoperative results after valve replacement. Eur Heart J 1985; 6 (Suppl 1): 33. (Abstr).

[7] Schuler G, Peterson KL, Johnson A et al. Temporal response of left ventricular performance to mitral valve surgery. Circulation 1979; 59(6): 1218.

[8] Kennedy JW, Doces JG, Stewart DK. Left ventricular function before and following surgical treatment of mitral valve disease. Am Heart J 1979; 97: 592.

[9] Phillıps HR, Levine FH, Carter JE et al. Mitral valve replacement for isolated mitral regurgitation: Analysis of clinical course and late postoperative left ventricular ejection fraction Am J Cardiology 1981; 48: 647.

[10] David TE, Uden DE, Strauss HD. The importance of the mitral apparatus in left ventricular function after correction of mitral regurgitation. Circulation 1983; 68: II-76.

[11] Kronzon I, Cohen ML, Winer HE et al. Left ventricular outflow obstruction: A complication of mitral valvuloplasty. J Am Coll Cardiol 1984; 4(4): 825.

[12] Gallerstein PE, Berger M, Rubenstein, S et al. Systolic anterior motion of the mitral valve and outflow obstruction after mitral valve reconstruction. Chest $1983 ; 83(5)$ : 819 